\title{
CD4 count and viral load response to different anti retroviral treatment regimen among AIDS patients from Mumbai, Western India
}

\author{
Umapathy Shankarkumar*1, Aruna Pawar ${ }^{1}$, Amar Pazare ${ }^{2}$ and \\ Kanjaksha Ghosh²
}

Address: ${ }^{1}$ National Institute of Immunohaematology 13th Floor, KEM Hospital, Parel, Mumbai - 400012, India and ${ }^{2}$ Department of Medicine, KEM Hospital, Parel, Mumbai - 400012, India

* Corresponding author

from Frontiers of Retrovirology: Complex retroviruses, retroelements and their hosts

Montpellier, France. 21-23 September 2009

Published: 24 September 2009

Retrovirology 2009, 6(Suppl 2):P8I doi:I0.II86/I742-4690-6-S2-P8I

This abstract is available from: http://www.retrovirology.com/content/6/S2/P8I

(c) 2009 Shankarkumar et al; licensee BioMed Central Ltd.

\section{Background}

The viral load test provides important information that is used in conjunction with the CD4 cell count: to monitor the status of HIV disease, to guide recommendations for therapy, and to predict the future course of HIV, decreases the complications of HIV disease and prolongs life. As per National AIDS Control Organization (NACO) Guidelines HIV-1 infected patients are treated with either one of the primary line regimen as follows SLN (Stavudine + Lamivudine + Nevirapine) Group A, ZLN (Zido-vudine + Lamivudine + Nevirapine) Group B, SLE (Stavudine + Lamivudine + Efavirenz) Group C, ZLE (Zidovudine + Lamivudine + Efavirenz) Group D.

\section{Materials and methods}

A total of 214 HIV-1 infected patients attending the virology OPD of KEM Hospital who were on Primary line ART were recruited for the study. All these patients were evaluated for their CD4 Count by using BD Flowcytomter and their plasma RNA Viral Load by Taqman Probes using Roche RT-PCR machine.

\section{Results}

In $214 \mathrm{HIV}-1$ infected Group A (SLN) patients showed mean CD4 count 330.5 that was 278.6 six months ago. Mean CD4 count of Group B (ZLN) was 306.6 six months ago and now decreased to 256.3. Mean CD4 count of Group C (SLE) was 244 six months ago and changed to
181.5. Group D (ZLE) patients showed slight decrease in the mean CD 4 count. A total of $42 \%$ patients had Gastro intestinal discomfort and Insomnia. 7 patients on ZLN regimen, 2 patients on SLE regimen had viral load more than 1000 copies/ml. No patients from ZLE regimen had viral load above 1000 copies/ml. Widely used SLN regimen patients had viral load ranging from 1042 copies $/ \mathrm{ml}$ to $31,13,018$ copies $/ \mathrm{ml}$. Out of $214 \mathrm{HIV}-1$ infected patients, 30 patients showed a range of viral load copies from 57 to $31,13018.17$ out of 30 patients were on SLN (Group A). 50\% among them showed viral load more than 9000 copies/ml. 9 patients out of 30 were on Group B (ZLN). More than 50\% among these had viral load above 15,000 copies/ml. Only 2 patients of each Group C (SLE) \& Group D (ZLE) had increased viral load. Recommended ART regimen is expected to decrease viral load and increase CD4 count.

\section{Conclusion}

Our Study confirms that The HIV cross clade variants is produced depending on the antiretroviral drug and the host genetic factors. 